\title{
Research on Innovative Practice of Ideological and Political in College English Courses
}

\author{
Yinya Huang \\ Zhejiang Yuexiu University, Shaoxing, China \\ Email: 20131050@zyufl.edu.cn
}

How to cite this paper: Huang, Y.Y. (2021) Research on Innovative Practice of Ideological and Political in College English Courses. Open Access Library Journal, 8: e7600. https://doi.org/10.4236/oalib.1107600

Received: May 31, 2021

Accepted: July 26, 2021

Published: July 29, 2021

Copyright $\odot 2021$ by author(s) and Open Access Library Inc.

This work is licensed under the Creative Commons Attribution International License (CC BY 4.0).

http://creativecommons.org/licenses/by/4.0/

\section{(c) (i) Open Access}

\begin{abstract}
In recent years, global economic integration has a great impact on college students' thinking. Many college students are lack of ideals and beliefs and their moral consciousness is very weak and ideological quality is not high. Therefore, ideological and political education should be carried out in college English teaching. We need to make scientific and reasonable teaching program. It will help to improve the overall quality of college English teaching and the ideological quality of college students. Based on this, the paper summarizes the practical value of curriculum ideology and politics in college English teaching. It also analyzes the advantages of curriculum ideology and politics in college English teaching. To provide some reference for college teaching, the paper even explores the practical path of curriculum ideology and politics in college English teaching.
\end{abstract}

\section{Subject Areas}

Educational Reform, Language Education

\section{Keywords}

College English, Curriculum Ideology and Politics, The Teaching Innovation

\section{1. 前言}

高校开展的思政工作直接关系到人才培养的实际质量。习总书记早在十 八大就已强调, 高校需将立德树人当作中心环节, 在整个教育过程之中对思 政工作进行贯彻落实, 做到全程育人以及全面育人。所以, 高校当中的思政 工作除了是所有思政工作人员与思政课程的重要使命、任务, 同时也是所有 教职员工以及所有课程的使命、任务 [1]。在国内高校当中，英语学科拥有广 泛受众群体, 是课程思政的一个重要阵地。但是现阶段的大学英语课程, 教 
师教学过程形式比较传统单一, 不能很好的把思政元素和学习内容自然结合 起来。很多时候, 不能做到, 既让学生学到丰富的大学英语知识, 又接受到 新方式的思想政治教育。高校当中的英语教师需在实际教学当中对课程思政 这个理念加以积极渗透, 促使大学生实现健康、长远发展。为此, 对高校英 语教学当中课程思政的具体实践路径展开探究有着重要意义。

\section{2. 高校英语教学当中课程思政的实践价值}

让学生了解社会主义核心价值观的主要内容固然重要, 但坚持知信行合 一, 将社会主义核心价值观内化为学生的精神追求、外化为学生的自觉行动 才是目标所在。大学教育的各类专业课的教学内容不同, 但都承担着培养担 当民族复兴大任时代新人的重任, 都应当结合专业背景引导学生将小我融入 大我, 把国家、社会、公民的价值要求融合为一, 并体现在实际行动中。

\section{(一) 有助于提升大学生综合素养}

国内高校当中的专业教学以及思政教育一直呈现出割裂状态, 专业课着 重进行专业知识有关教育活动, 思政课程主要承担思政教育这个重任[2]。专 业教学与思政教育很难产生交集, 这样就导致思政方法、内容以及效果全都 存在局限性, 使得一些大学生出现专业素质较强, 但思政修养比较差这种问 题。实际上, 课程思政是要求专业课程以及公共课程全都承担思政教育这个 重任, 把思政教育与专业教学进行有效结合 [3]。在高校英语教学当中进行课 程思政这项工作, 不仅可以培养大学生听说读写这些能力, 同时还能有效提 升大学生政治修养与思想道德, 促使大学生实现全面发展, 提高人才培养的 整体价值。

\section{（二）有助于对教学内容进行有效充实}

课程思政具有的核心任务是在各科教学当中对爱国主义这种思想加以渗 透, 通过专业教学培养大学生政治修养与道德素质 [4]。在高校英语教学之中 对课程思政这项工作进行切实落实, 必然会融入爱国主义有关教学素材, 比 如新闻素材以及时政材料等, 能够对英语教学具体内容进行充实。同时, 英 语教师可以把自身生活感受以及经验当作立足点, 向大学生传递一些健康积 极的思想观念。如此一来, 可以改变过去高校教学期间单纯对专业知识进行 讲授的局面, 促使大学生对于所学知识产生新的感受。大学生可以受到一些 思想熏陶、情感引导以及政治教育, 进而积极主动的对英语知识进行学习以 及探究, 有效提升英语教学实际效率以及质量, 顺利完成思政教育与专业教 育目标。

\section{（三）有助于强化课程的协同效应}

高校英语和其他课程一同进行课程思政这项工作期间, 能够形成协同育 人这种效应。第一, 高校英语和专业课、公共课以及实践课程协同进行课程 思政这项工作, 能够把各门课程具有的知识特点以及教学特点当作立足点, 站在不同角度对大学生素质以及能力进行培养, 促使大学生成为有道德、有 理想、有知识的优秀人才。第二, 高校英语和其他课程一同进行课程思政这 项工作, 有助于激发大学生进取心与责任心, 帮助其树立起远大目标, 努力 提升自身英语学习的实际效率以及质量, 进而促使英语教学实际效率不断提 
高。第三, 高校英语和其他课程一同进行课程思政这项工作, 把课程思政当 作纽带, 增强各门课程的配合度, 可以促使专业知识整体教学质量有效提高。

\section{3. 高校英语教学当中进行课程思政的优势}

高校英语围绕听说读写有关知识与教学工作展开, 特殊教学模式以及内 容形成高校英语学科课程思政这项工作具有的独特优势 [5]。

\section{（一）通过多种不同方式进行思政教育}

在高校当中, 通过英语教学着重培养大学生听说读写这些能力, 进而形 成四类不同的教学内容, 各项内容全都拥有鲜明的知识特征以及教学方式, 给课程思政这项工作的开展提供很多方法, 能够多角度、全方位的对大学生 实施思政教育 [6]。在听力模块当中, 英语教师可引入一些和思政教育存在关 联的简短听力材料, 借此对大学生进行初级性与简单化的思政熏陶。在口语 模块当中, 英语教师可在大学生间进行思政对话, 通过简单的口语交流, 融 合相关的思政信息与内容, 促使大学生在交流互动当中逐渐形成健康、正确 的思想观念。在阅读模块当中, 英语教师可引入一些具有深度、比较长的思 政教育有关英语材料, 让大学生通过阅读、推理、分析这些过程对正确思政 理念进行掌握。在写作模块当中, 英语教师可制定相关的英语思政主题, 组 织大学生进行写作活动, 促使大学生阐述自身对思政主题的具体认识。通过 多种不同的教学方式, 能够多角度、全方位的培养大学生思想素质, 有效提 高大学生的政治修养。

\section{（二）开展对话性思政教育}

在高校课程之中, 英语教学属于语言教育, 其具有非常显著的对话特征, 教师可在课堂教学当中引入可以培养大学生听说读写的所有素材与议题, 将 这些素材以及议题当作大学生学习的重要材料, 形成师生对话的主题。英语 教师可对材料介绍以及知识分析的机会加以充分利用, 向大学生传递健康积 极的思想观念, 有效提升大学生的思政修养。比如, 开展口语教学期间, 英 语教师可引导大学生讨论 “ 新冠肺炎” 这个议题, 教师需鼓励大学生运用英 语说一说自身预防新冠、规避谣言的做法。教师对学生观点进行点评之时, 需融入健康积极、充满正能量的案例与思想观念, 积极引导大学生主动提升 自身语言能力与行为修养, 有效培养其感恩意识。借助对话能够有效培养大 学生思政修养, 促使课程思政这项工作的整体质量不断提高[7]。

\section{（三）开展人文性思政教育}

高校英语学科教学内容具有人文性这个特征, 不仅涉及很多历史事件、 时事政策以及社会新闻, 同时还涉及到很多哲学思想、文学知识以及艺术知 识。上述内容自身便具有显著的感染性、教育性以及引导性的特征, 特别是 听力素材、写作参考以及阅读资料, 本身就是思政内容, 拥有思政教育的功 能与价值。教学期间, 英语教师对人文性有关知识进行讲解之时, 可以直接 开展思政教育。比如, 一些阅读材料比较分析我国和其他国家当中的政治体 制具有的特征, 着重强调中国特色社会主义具体产生背景以及优势。一些阅 读材料通过讲述历史故事以及社会事件这种方式对仁义礼智信这些核心思想 进行传递, 一些内容十分感人, 可以促使学生进行深入思考, 可以净化学生 
心灵, 并且塑造学生品质。以上都是其他课程对课程思政这项工作加以落实 期间不具备的一些优势, 可以突显出在英语教学当中进行课程思政这项工作 具有的独特价值。

\section{4. 高校英语教学当中课程思政的具体实践路径}

\section{（一）设置专业教学与课程思政双重目标}

一般来说, 教学目标不仅决定教师对课程任务的具体认识, 同时还统领 课程计划的编制和实施 [8]。在高校当中, 英语教师应当对课程思政这项工作 开展的必要性以及紧迫性加以充分认识, 对于课程思政的具体含义以及内容 进行深入研究, 改变过去英语教学单纯把知识教育当作主体的目标机制, 进 而形成课程思政与专业教学双重目标[9]。同时, 英语教师要将上述两个目标 置于同等地位, 遵循互促、交融的原则, 借助英语课程目标完成课程思政对 应目标, 同时用课程思政来辅助英语教学, 二者存在紧密关联, 是相辅相成 的, 可以协同提升大学生综合能力以及综合素养。

\section{(二) 制定深入且系统的教学计划}

为践行课程目标, 对教学工作进行有效指导, 英语教师需制定科学可行 的教学计划。英语教师对双重目标进行设定医护, 应当把听说读写有关知识 当作立足点, 建立系统性的课程思政有关教学计划。首先, 英语教师要对各 个知识模块对应的课程思政的具体任务进行详细设计。比如, 听力模块主要 是让大学生对一些简单思政事件进行了解与掌握 [10]。在口语模块当中, 英语 教师可引入一些大学生非常关注的社会热点以及思政现状, 促使大学生逐渐 形成正确思政观念。在阅读模块当中, 英语教师可以增加一些系统性以及深 入的思政知识, 促使大学生在积极思考以及分析推理这个过程之中逐渐提升 自身政治修养。在写作模块当中, 英语教师可以鼓励大学生对一些正能量思 想以及观点进行大胆表述。其次, 教师可围绕着每个模块对应的思政目标以 及内容特征, 选择兼具思政教育以及专业知识双重特点的素材, 给大学生提 供合适的教学内容。最后, 教师要按照宏观规划以及逐层递进这个原则, 重 视各个模块间的内容配合, 有效提升课程思政具有的协同性以及有序性。

\section{（三）根据大学生反馈对思政教学进行灵活调整}

高校英语拥有人文性以及对话性两种显著特征, 多数内容是在师生对话 当中进行的。所以, 英语教师按照教学计划进行思政工作期间, 需要把大学 生反馈当作依据, 对课程思政现有教学方法以及内容进行灵活调整。英语教 师在和大学生进行对话, 对大学生的写作内容以及阅读材料进行点评期间, 应当按照大学生传递出来的观念以及思想灵活选择和其表述存在关联的思政 内容, 有效提高教育整体有效性。如此一来, 不仅需要教师具备课程思政这 种意识以及专业知识, 可以有针对性的开展教育活动, 同时还要求教师拥有 良好政治、道德以及思想观念。此外, 教师还需不断强化自身学习, 提升自 身具有的思政素养，进而为进行思政工作打下坚实基础。

\section{（四）通过方法创新强化课程思政具有的实效性}

实际上, 思政教育的内容具有较高的时效性, 并非固化的, 教师需从大 学生关注点入手, 要找准时机, 在课堂教学当中对思政教育有关内容进行巧 
妙融入, 在这之中, 对教学方法进行合理选择至关重要。第一, 课堂之上, 英语教师应当有意识的对多媒体进行运用, 通过动画、视频以及音频方式对 教学内容加以呈现, 这样可以对枯燥知识进行生动化以及形象化, 同时还能 有效激发大学生学习兴趣。第二, 英语教师需尽可能的运用不同方式带动教 学气氛, 例如组织大学生进行角色扮演、英语辩论、知识竞答以及主题演讲 等。为促使大学生主动积极的参与到这些活动当中, 教师可实施翻转教学, 突出大学生在课堂之上具有的主体地位, 深入挖掘大学生具有的潜能。第三, 教师需有意识的组织大学生进行合作学习, 强化师生与生生间的互动交流。 例如, 英语教师可多搜集一些和社会热点有关的英语报道, 积极鼓励大学生 对其中某个问题进行英语演讲, 由其他同学对这名学生的演讲做出客观评价。 这样一来, 可以促使生生之间进行思想碰撞, 促使所有学生完善自身观点, 有效提高其听说能力, 促使大学生关注一些时事热点。第四, 英语教师可让 大学生搜集身边一些英文翻译, 如景点、道路以及商场等, 之后进行汇报整 理, 通过小组形式在课堂之上进行交流讨论, 对其中一些可取之处以及不足 之处进行重点分析。在此过程之中, 可以有效提高大学生英语能力, 强化其 团队意识与合作精神 [7] [8] [9] [10]。第五, 英语教师可对网络技术加以运用。 例如, 运用智能化评阅系统, 把慕课、微课和教学进行结合, 借此激发大学 生英语学习兴趣, 促使其主动融入到英语学习之中。

\section{(五) 运用与英语特点相符合的评价方式}

通过有效评价能够引导大学生逐渐形成健康积极的思政观念。现阶段, 高校当中的英语教师可由课堂表现以及课后考核这两个方面对大学生思政学 习的具体结果加以评价。第一, 课堂之上, 英语教师需及时表扬以及鼓励对 正确观念进行传递、具有正能量的大学生, 借此引导大学生对自身思政观念 进行积极表达, 创设良好学习环境, 促使大学生逐渐形成健康积极的思政观 念以及行为。第二, 教学结束以后, 英语教师对考试题目以及评分标准进行 设计之时, 需与考试内容进行结合, 引入一些思政素材, 针对表达正确积极 思政观念、对正能量进行传递的大学生, 英语教师需给出高分, 增强大学生 提升自身思政修养的行为与意识。

\section{5. 结论}

综上可知, 在课程思政这个背景之下, 高校英语教改需努力把听说读写 译这些语言技能方面教育与思政教育进行结合, 这样有助于提升大学生综合 素养, 有助于对教学内容进行创新, 同时有助于强化课程的协同效应。然而, 思政结合英语教育不是一蹴而就的事情, 现在的英语教学更多的还是关注自 身的教学任务。学校和教师需要让学生树立正确的爱国情操和民族精神, 英 语教师也需要担负起育人的作用, 确保英语教师, 英语教材和教学制度三个 因素在思政教育实施过程中得到相互补充和作用。高校教师可通过多种不同 方式进行思政教育, 开展对话性思政教育以及人文性思政教育, 设置专业教 学与课程思政双重目标, 制定深入且系统的教学计划, 根据大学生反馈对思 政教学进行灵活调整, 通过方法创新强化课程思政具有的实效性, 同时运用 与英语特点相符合的评价方式, 进而帮助大学生对专业知识进行掌握, 有效 
提高其思政修养。

\section{Conflicts of Interest}

The author declares no conflicts of interest.

\section{References}

[1] 雷盛燕. 课程思政理念下 POA 理论在大学英语智慧教学创新模式中的应用[J]. 通化师范学院学报, 2021, 42(5): 127-133.

[2] 王龙. 课程思政理念下理工科院校大学英语读写课程的教学设计与实践 [J]. 湖北 开放职业学院学报, 2021, 34(8): 91-92+97.

[3] 霍娜. 基于 “课程思政”大学英语教育教学实践体系研究 [J]. 继续教育研究, 2021(3): 126-129.

[4] 翁翠. 信息化教学背景下的大学英语课程思政的实践研究 [J]. 科学咨询(教育科 研), 2021(4): 65-66.

[5] 全小燕. 融合课程思政的大学英语混合式教学实践研究 [J]. 对外经贸, 2021(3): 131-133.

[6] 林芳. 基于在线混合式教学的大学英语课程思政研究与实践 [J]. 武汉船舶职业技 术学院学报, 2021, 20(1): 133-137.

[7] 时园园. “课程思政”融入大学英语教学的实践探索——以抗疫时期的大学英语教 学为例 [J]. 海外英语, 2021(6): 170-171.

[8] 柴金莲. 混合式教学模式下大学英语课程思政教学实践分析 [J]. 英语广场, 2021(7): 64-67.

[9] 夏海玲. 课程思政视域下大学英语演讲教学实践与 MF 教学模式探究 [J]. 校园英 语, 2021(6): 33-34.

[10] 袁璐. 课程思政视角下在线大学英语教学中使用网络新闻英语的实践反思 [J]. 中 国多媒体与网络教学学报(上旬刊), 2021(2): 163-166.

\section{Appendix (Abstract and Keywords in Chinese)}

\section{大学英语 “课程思政” 教学创新实践研究}

摘要: 近些年来, 全球经济一体化给大学生思想造成极大冲击, 不少大 学生都出现了缺少理想信念、道德意识非常薄弱以及思想素质不高这些问题。 所以, 在高校英语教学当中开展课程思政方面教育, 制定科学合理的教学方 案, 有助与提升高校英语教学整体质量, 并且有助于提升大学生具有的思想 素质。基于此, 本文在对高校英语教学当中课程思政的实践价值加以概述的 基础上, 对高校英语教学当中进行课程思政的优势加以分析, 进而对高校英 语教学当中课程思政的具体实践路径展开探究, 希望能为高校教学提供些许 参考。

关键词: 大学英语, 课程思政, 教学创新 